\title{
IS PRE-CONTROL THEORY REALLY A SHORTCUT TO ESTIMATE THE PROCESS CAPABILITY INDEX?
}

\author{
Onkar Pathak \\ Operations Management \\ Weschool, Mumbai, Maharashtra, India
}

\begin{abstract}
This case study is devoted to the subject of process capability $(C p)$, process capability index $(C p k)$, and the contribution of pre-control theory in evaluating the process capability index $(\mathrm{Cpk})$. The pre-control theory states that if the consecutive five samples are in the green zone then, the process capability will be of minimum 1.33 and there is no need of 50-100 samples required to determine the process capability index $(C p k)$. The objective of this investigation is to analyze whether a really pre-control theory is a shortcut way to decide the process capability $(C p)$ and the process capability index $(C p k)$ ? This case study is based on the continuous improvement of the manufacturing process of the adjustment screw. This experiment is performed in a pipes \& fittings manufacturing industry located in Mumbai, India.
\end{abstract}

Keywords - Pre-control Theory, Process Capability, Process Capability Index, Process Variability, Confidence Interval of Process capability Index, Quality, Control Charts

\section{INTRODUCTION}

Quality at the source is a lean manufacturing principle which states that quality should be checked and controlled not only at the end but also checked at every value-adding station. The quality at the source principle gives free hand to operators for checking the quality at each source of value addition. Quality assurance teams train operators about how to use control charts to identify the defects at the source and not let it go of the defects to the next station. This case study is conducted in an industry that manufactures pipes, valves, flanges, and fittings located in Mumbai, India. The objective of the quality at the source is to improve the quality and reduce the defects by studying the capability of the process. The capability of the process can be studied with the help of statistical tools developed from the normal distribution curve and the control charts. Every defect may have some causes and these causes are of the two types, first a random cause and other is an assignable cause. These causes can be judged by observing a pattern of data points on the control charts. Industries are using the pre-control charts or statistical process control charts to study the process capability of the operations. A pre-control chart is the easiest, more cost-effective, and time-saver tool to study the capability of the process and identify the cause of defects. The Process Capability is the statistical tool that measures process spread with respect to the specification width provided by the customer. The process capability index is the tool use to identify the centering of the sample mean with respect to the target mean provided to the manufacturer by the customer. The process capability indices are helpful management tools, especially in the manufacturing process, which give regular quantitative measures of manufacturing capability and production quality. With the fast progression of the manufacturing innovation, suppliers require their items to be of high caliber with an exceptionally low portion of defectives generally estimated in parts per million. Nowadays most supplier certification manuals include a view of process capability analysis and describe the recommended procedure for computing a process capability index. The procedure of computing the process capability index is either by using the statistical process control charts or by using the pre-control theory. Bhote \& Bhote [1], Pre control theory states that "If consecutive 5 units are in the green zone of the pre-control chart, the process is in control and the process capability index will automatically result into a min of 1.33 and hence, there is no need to take the sample size of 50-100 units for measurement of the process capability index". This experiment studies the effectiveness and reliability of precontrol charts in determining the process capability index. Also experiment further studies the application of confidence interval and point estimates to predict the true process capability index of the process to fulfill the customer's requirement of minimum process capability index of 1.33 [24-5-6]. To ensure the qualification of the customer's requirement of process capability 1.33 , the manufacturer needs to ensure the lower bound of the confidence interval should have a value greater than 1.33 [7]. Proposed an expression that cites the sample mean and average range to drive the minimum dispersion or standard deviation and achieve the desired lower confidence level of the process capability index of 1.33 


\section{International Journal of Engineering Applied Sciences and Technology, 2020 Vol. 5, Issue 3, ISSN No. 2455-2143, Pages 383-392 \\ Published Online July 2020 in IJEAST (http://www.ijeast.com)}

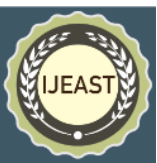

\section{PROPOSED THEORY}

\section{A. Methodology}

- Understand the basic concepts of process capability

- Understand the concept of pre-control theory

- An Argument based on the pre-control theory

- Collection of process data

- Construction of a pre-control chart

- Normality test to ensure the data is normal

- Validate the requirements of data for calculating the process capability index

- Estimation of $C_{p} \& C_{p k}$

- Estimation of the confidence intervals of $C_{p k}$

- Validate the critical assumptions made over the Precontrol theory

- Create a model that establishes a relation between the average Range and lower confidence level of $C_{p k}$

- Calculate the required average range to obtain the desired lower confidence level of $C_{p k}$

\section{B. Process Capability and Process Capability Index \\ 1. Process Capability}

Process Capability is the ratio of specification width provided by the customer to the actual spread of the process determined by the width of the normal distribution curve denoted as " $6 \sigma$ ". It compares and relates the Process Width with the Specification Range. Process capability is a measure of spread [1].

$$
C_{p}=\frac{\text { Specification Width }(S)}{\text { Process width }(P)}
$$

Process Capability based on lower specification limit $\left(C_{p l}\right)$ $: C_{p l}$ measures how close the process mean is running to the lower specification limit. It estimates the process capability for specifications that consist of a lower limit only.

Process Capability based on upper specification limit $\left(\boldsymbol{C}_{p u}\right): C_{p u}$ measures how close the process mean is running to the upper specification limit. It estimates the process capability for specifications that consist of an upper limit only.

\section{Process Capability Index}

$$
\begin{aligned}
& S=\text { Specification Width } \\
& D=\text { Design Center } \\
& \bar{X}=\text { Process Average } \\
& k=\text { Correction factor } \\
& P=\text { Process Width }
\end{aligned}
$$

$$
\begin{gathered}
K=\frac{\bar{X}-D}{S / 2} \text { OR } \frac{D-\bar{X}}{S / 2} \\
C_{p k}=(1-K) C_{p}
\end{gathered}
$$

Bhote $\&$ Bhote [1] states that the process capability $C_{p}$ only deals with the ratio of the specification width and the process width, process capability does not take non-centering of the process mean into account. Whereas, the process capability index $C_{p k}$ is the parameter which considers the non-centering of the process mean with respect to specification limit. This non-centering of the process mean involves variation and thus, reduces the margin of safety. In order to interpret this noncentering a correction factor introduced as ${ }^{\prime \prime} \mathrm{K}^{\prime}$. When the process average $\bar{X}$ coincides with the design center $D$ at the target value, then $K$ reduced to zero and the magnitude of $C_{p}$ and $C_{p k}$ becomes equal. When the process average $\bar{X}$ skews towards one end of the specification limit away from the design center $D$ then, the magnitude of $K$ increases, and the value of $C_{p k}$ reduces as compared to the value of $C_{p}$. Process spread and non-centering of process mean are the important parameters that affect the quality of the process and also cause variation. In the process improvement, non-centering of the process mean is easy to drift but, reducing the process spread is a difficult task. $C_{p k}$ is an excellent tool to measure the variability and process capability because it considers both process spread and non-centering of process width. Achieving $C_{p k}=2$ is nothing but achieving the zero defect and zero variation in the process.

\section{Pre-control Theory}

Pre-control is also known as the stoplight control. Pre-control was developed to monitor the proportion of non-confirming units or defects produced in the manufacturing process. The pre-control chart is basically divided into three groups: Green, yellow, and red; where the colors loosely correspond to good, questionable, and poor quality products. The number of green, yellow, and red units observed determines whether to start the production or stop the production and when to stop and adjust the process. The objective of pre-control is to identify when the quantity of non-confirming units or defects produced is very large. Thus, the pre-control theory helps to identify and monitor the process capability of the process and provides a sampling interval to ensure that the process capability index remains large. To construct the pre-control chart, the first step is to divide the specification width by 4 . The boundaries of the middle half of the specification limit are known as the Precontrol line (P-C). The area between these pre-control lines is called the green zone. The two areas between the pre-control line and the Specification line are called yellow zones. The two areas beyond the specific lines are known as res zones. When the specification width is equal to the process spread 
assuming a normal distribution curve, $86 \%$ of the curve falls into the green zone and $7 \%$ of the curve falls into the lower yellow zone, and the remaining $7 \%$ of the curve falls into the upper yellow zone. Using the multiplication theory, the probability of falling a pair of units into the yellow-red zone is $0.49 \%$, and there is only a $2 \%$ chance of falling the units outside the pre-control lines [1].

\section{EXPERIMENT AND RESULT}

\section{A. Hypothesis Formation}

\section{Objective}

To establish a hypothesis and examine whether really the precontrol theory is reliable and a shortcut way to determine the value of $C_{p k}$ and if not, provide an expression that will help the manufacturer to achieve a minimum true process capability index of 1.33 .

\section{Product Specifications}

The diameter of the adjustment screw is the critical parameter to qualify the customer's requirement. A $3.6 \mathrm{~mm}$ tool is used for the boring operation. Detailed specifications are shown in table 2 along with the product drawing shown in fig 1 .

\section{Data collection of consecutive 5 units}

After starting the production, consecutive 5 units of adjustment screws are recorded as shown in table 1 . These produced consecutive 5 units are in the green zone as plotted in the pre-control chart shown in fig 2.

\begin{tabular}{|c|c|c|c|c|c|}
\hline Sr No & \multicolumn{1}{|c|}{ Table 1. Data of 5 Consecutive Units } & \multicolumn{1}{l|}{5} \\
\hline 1 & 4.039 & 4.06 & 4.041 & 4.047 & 4.053 \\
\hline
\end{tabular}

\section{Establish hypothesis:}

Consider a sample of five consecutive units from the process. If all five units are within the green zone then, the process is in control i.e. the Process Capability Index $\left(C_{p k}\right)$ is equal to or greater than 1.33. In this case, if we notice all the consecutive units collected are in the green zone. According to the rule of pre-control theory, if consecutive 5 units are in the green zone then, Process Capability Index $\left(C_{p k}\right)$ is a minimum of 1.33. Hence, we established a hypothesis based on the pre-control theory.

\section{Ho:}

If consecutive 5 units are in the green zone then, the process capability index $C_{p k}$ of the process will be greater than or equal to 1.33

$C_{p k} \geq 1.33$

\section{H1:}

If consecutive 5 units are in the green zone then, the Process Capability Index $C_{p k}$ of the process would be less than 1.33 $C_{p k}<1.33$

Table -2 Product Specification

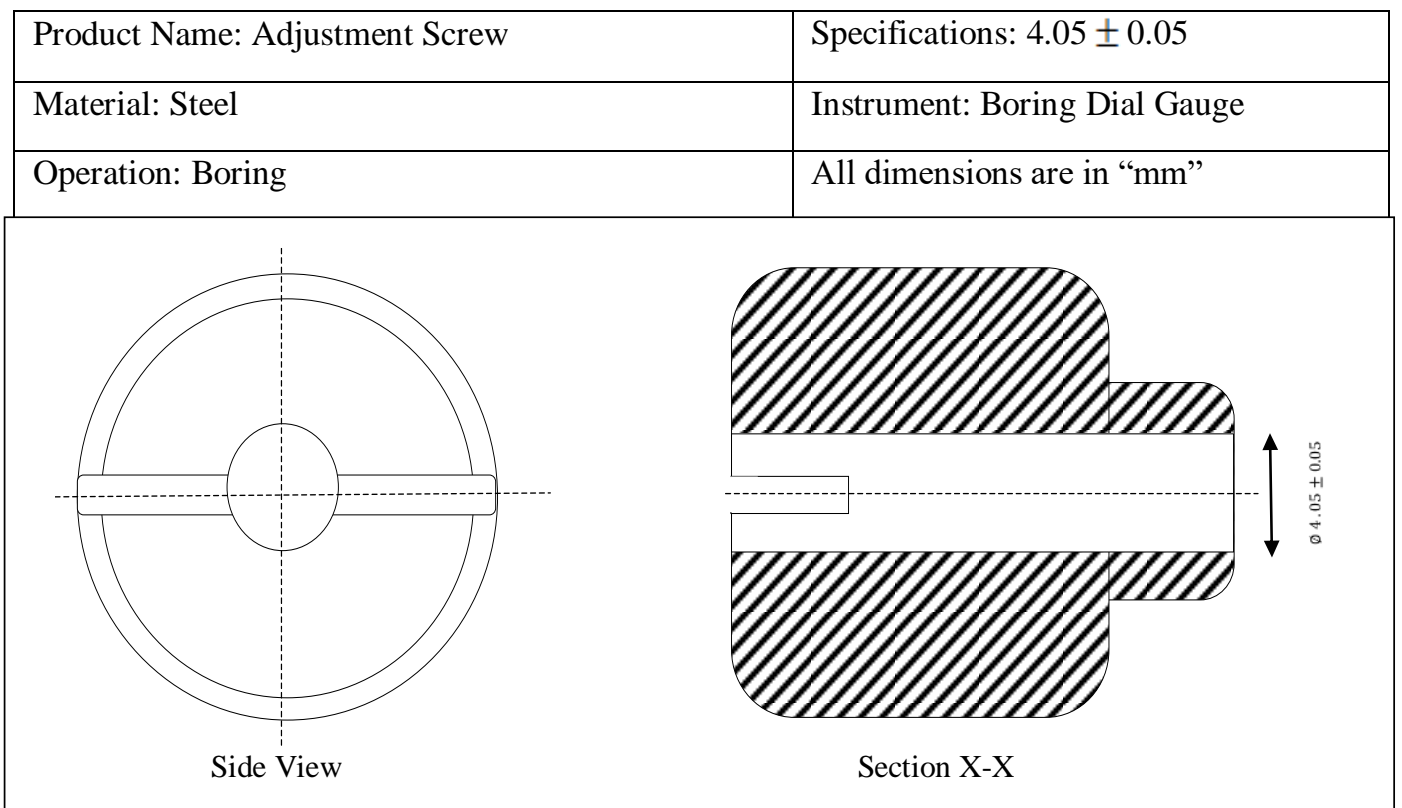

Fig.1. Product Drawing 
International Journal of Engineering Applied Sciences and Technology, 2020

Vol. 5, Issue 3, ISSN No. 2455-2143, Pages 383-392

Published Online July 2020 in IJEAST (http://www.ijeast.com)

Table -3 Data Record for 100 Units

\begin{tabular}{|c|c|c|c|c|c|c|c|}
\hline $\begin{array}{c}\text { Sample } \\
\text { No }\end{array}$ & 1 & 2 & 3 & 4 & 5 & $\overline{\mathbf{X}}$ & $\mathbf{R}$ \\
\hline 1. & 4.039 & 4.06 & 4.041 & 4.047 & 4.053 & 4.048 & 0.021 \\
\hline 2. & 4.045 & 4.04 & 4.052 & 4.057 & 4.055 & 4.0498 & 0.017 \\
\hline 3. & 4.05 & 4.046 & 4.049 & 4.043 & 4.051 & 4.0478 & 0.008 \\
\hline 4. & 4.042 & 4.044 & 4.048 & 4.058 & 4.056 & 4.0496 & 0.016 \\
\hline 5. & 4.046 & 4.041 & 4.05 & 4.055 & 4.058 & 4.05 & 0.017 \\
\hline 6. & 4.048 & 4.045 & 4.054 & 4.04 & 4.039 & 4.0452 & 0.015 \\
\hline 7. & 4.042 & 4.047 & 4.053 & 4.052 & 4.071 & 4.053 & 0.029 \\
\hline 8. & 4.043 & 4.049 & 4.05 & 4.078 & 4.03 & 4.05 & 0.048 \\
\hline 9. & 4.051 & 4.072 & 4.079 & 4.073 & 4.07 & 4.069 & 0.028 \\
\hline 10. & 4.056 & 4.044 & 4.078 & 4.059 & 4.06 & 4.0594 & 0.034 \\
\hline 11. & 4.057 & 4.043 & 4.047 & 4.069 & 4.057 & 4.0546 & 0.026 \\
\hline 12. & 4.06 & 4.048 & 4.046 & 4.029 & 4.063 & 4.0492 & 0.034 \\
\hline 13. & 4.068 & 4.056 & 4.065 & 4.049 & 4.055 & 4.0586 & 0.019 \\
\hline $14 .$. & 4.058 & 4.054 & 4.052 & 4.059 & 4.05 & 4.0546 & 0.009 \\
\hline 15. & 4.039 & 4.066 & 4.042 & 4.05 & 4.029 & 4.0452 & 0.037 \\
\hline 16. & 4.061 & 4.053 & 4.051 & 4.045 & 4.044 & 4.0508 & 0.017 \\
\hline 17. & 4.06 & 4.054 & 4.055 & 4.057 & 4.025 & 4.0502 & 0.035 \\
\hline 18. & 4.05 & 4.053 & 4.022 & 4.056 & 4.058 & 4.0478 & 0.036 \\
\hline 19. & 4.034 & 4.052 & 4.062 & 4.051 & 4.059 & 4.0516 & 0.028 \\
\hline 20. & 4.032 & 4.045 & 4.033 & 4.049 & 4.046 & 4.041 & 0.017 \\
\hline
\end{tabular}

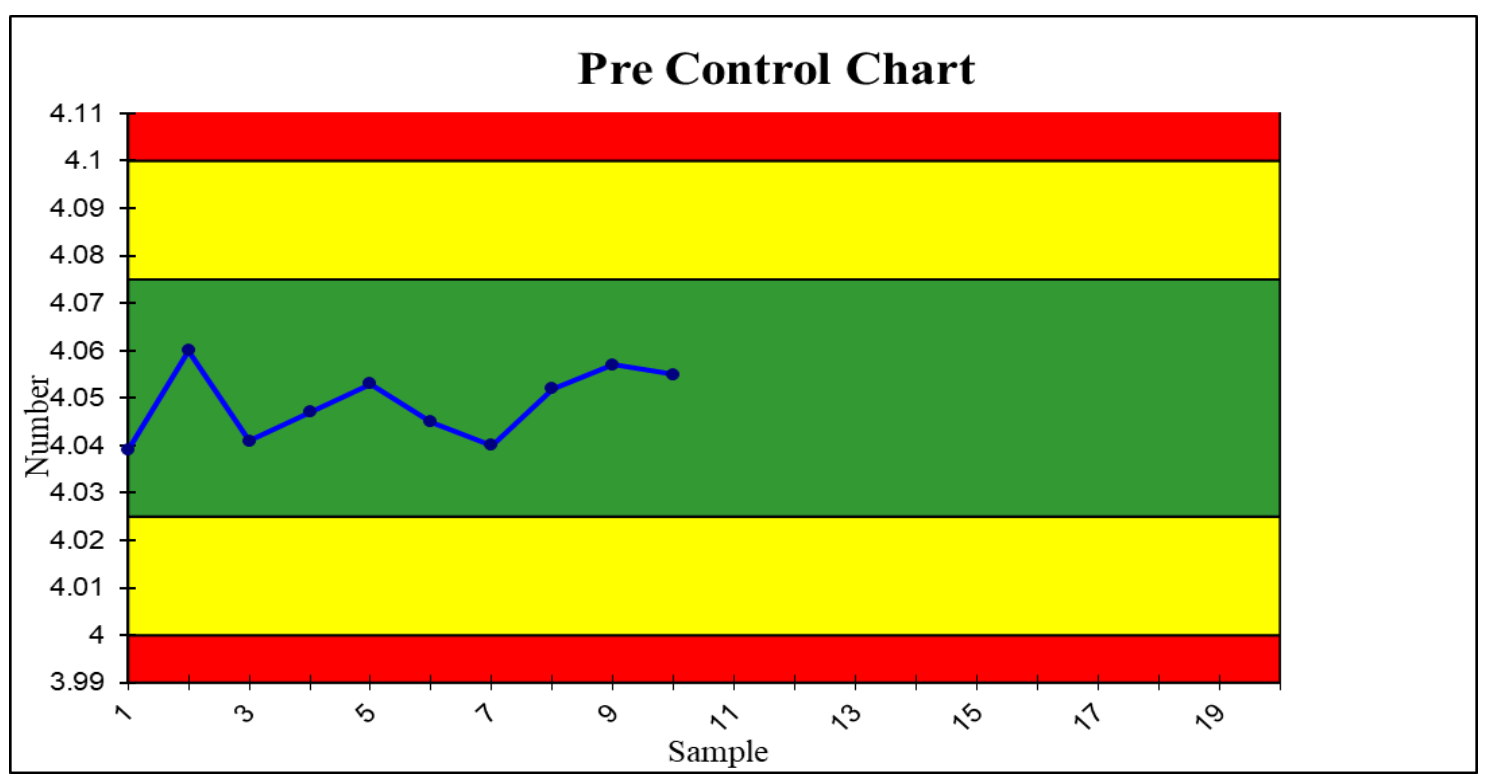

Fig.2. Pre-control chart for consecutive 5 units 


\section{Construction of a Pre-control Chart}

Data of 100 adjustment screws are recorded as shown in the table 3 and plotted on the pre-control chart in the form of 20 observations of subgroup size 5 as shown in the fig 3 . Data point of each sample is the average of 5 readings. All the 20 data points are observed in the green zone within pre-control lines. Hence, recorded data qualifies for calculation of the process capability study requirement.
6. Normal probability plot and Histogram to validate the data is Normal

To check whether the recorded data is normal, a graphical method of normal probability plot and the histogram is used as shown in fig 4 and 5 respectively. This data is analyzed in MINITAB-19. The data appears to be normal in the histogram diagram. The normal probability plot yields Anderson Darling test Static value of 0.571 and $p$-value of 0.135 which is greater than the significance level $\alpha=0.05$ hence, we can conclude that the data is normal and the curve is normally distributed.

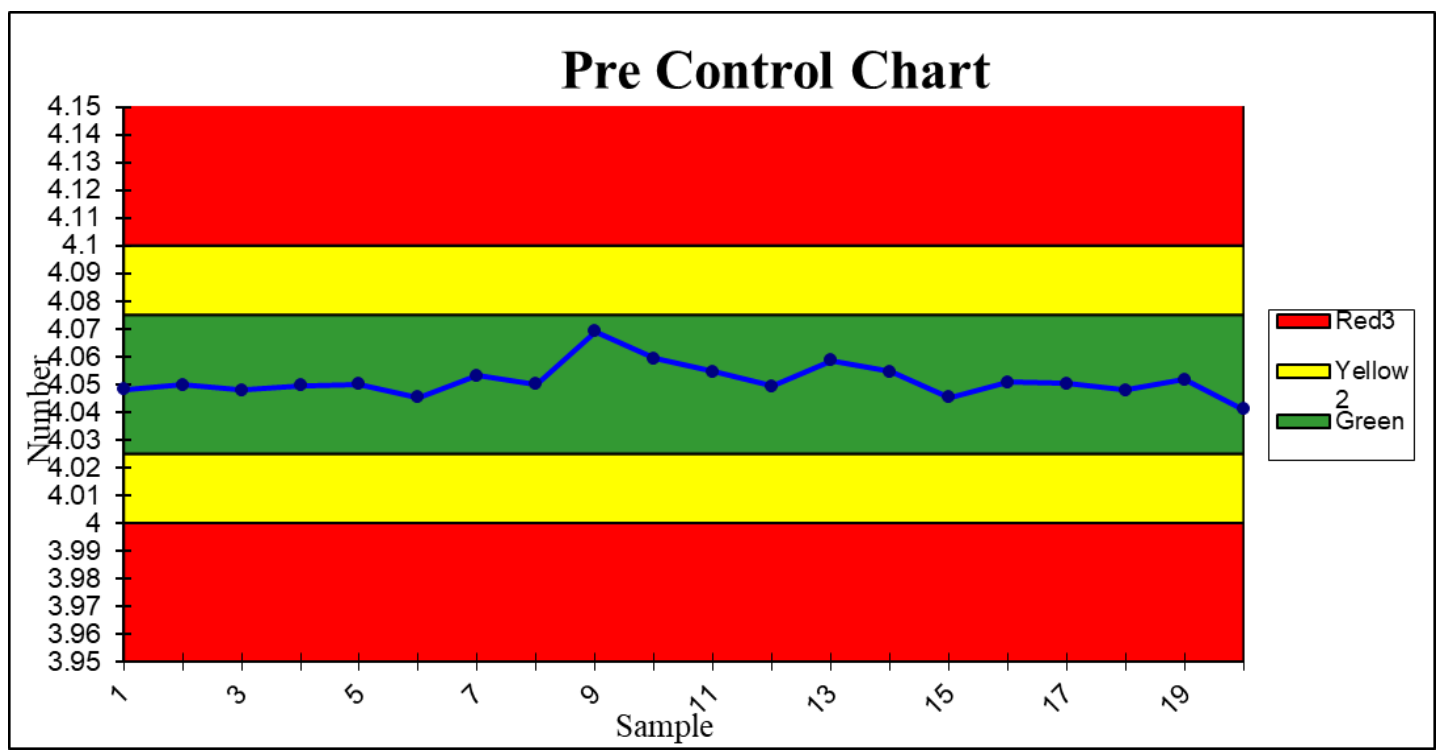

Fig.3. Pre-control Chart for consecutive 100 units

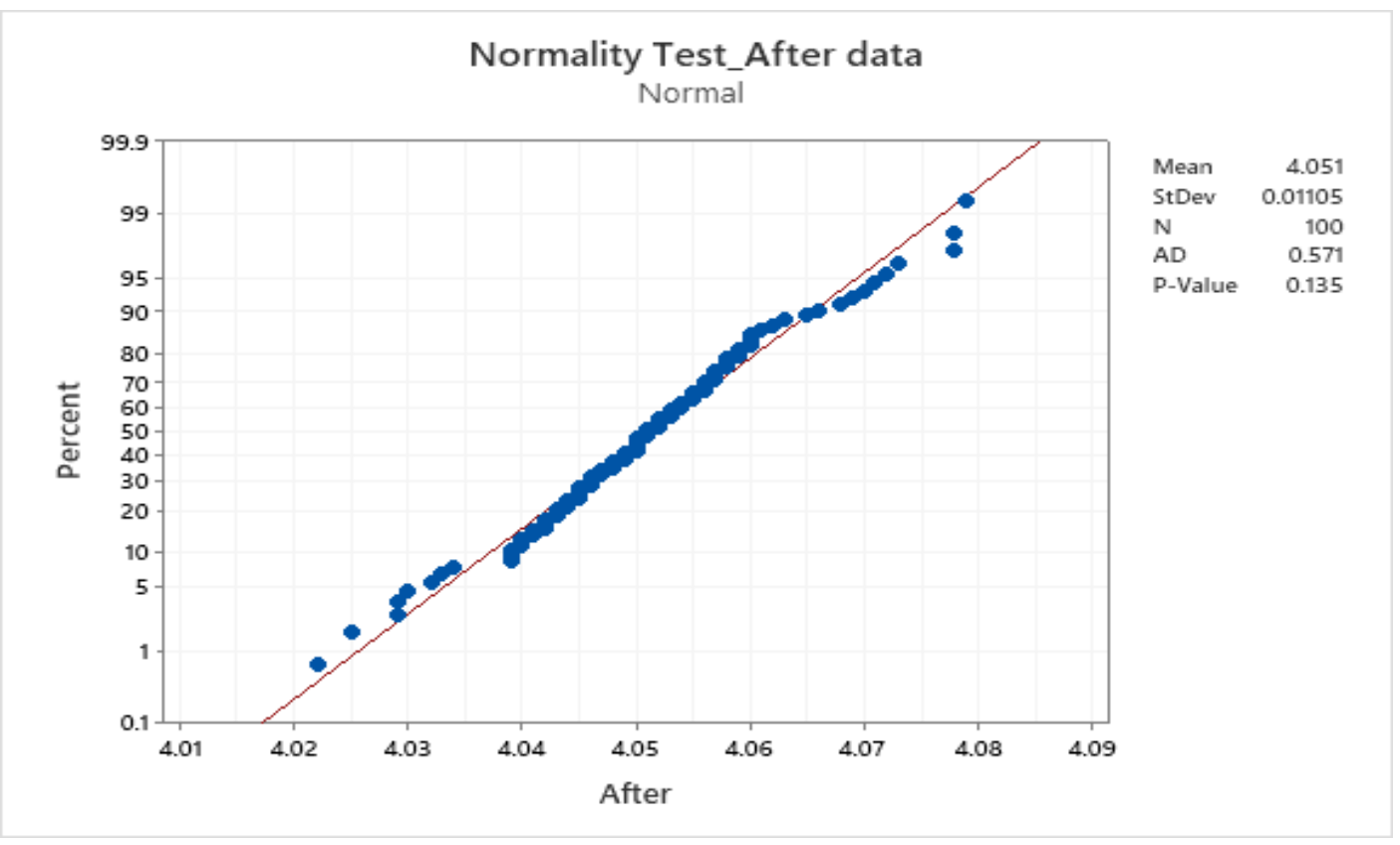

Fig.4. Normality Probability Plot 


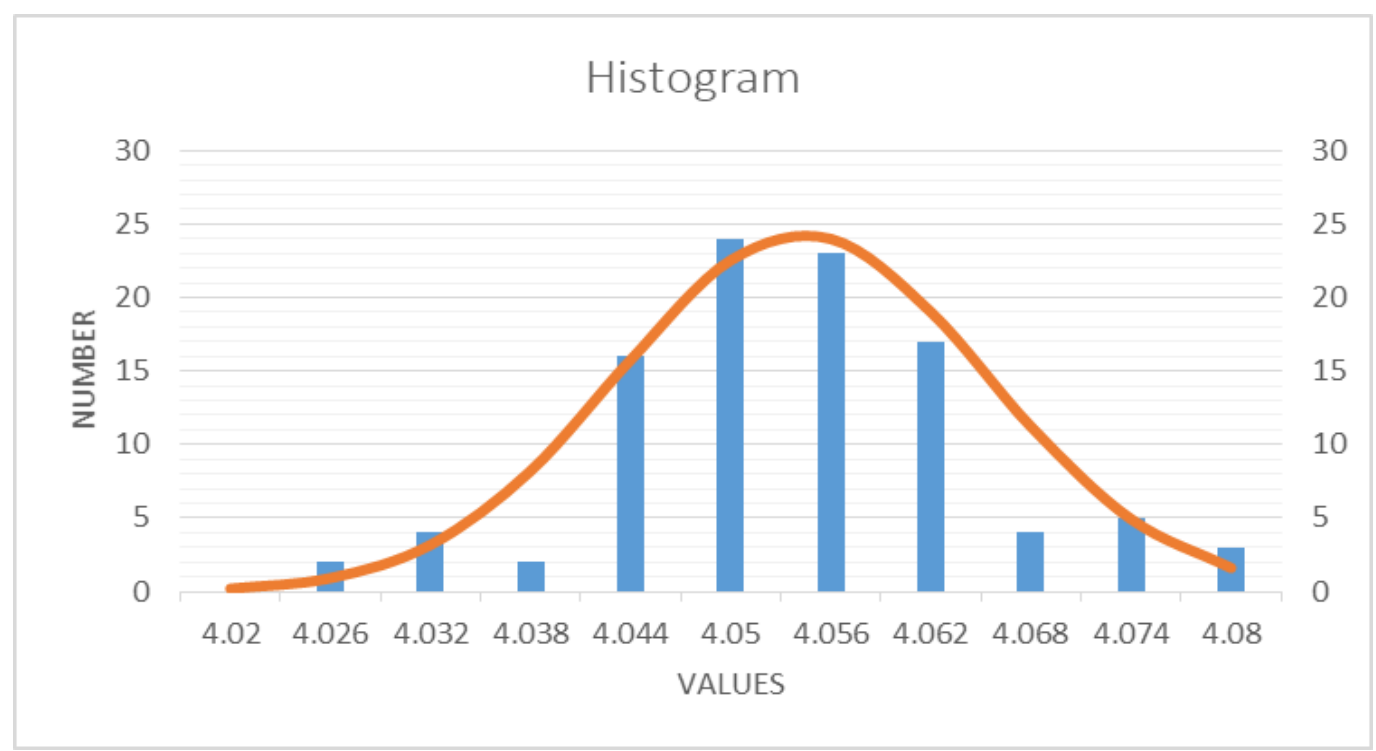

Fig.5. Normal Distribution Curve

\section{B. Hypothesis Testing}

1. Estimation of Sample Average $\overline{\bar{X}}$ and Standard Deviation $\hat{\sigma}$

From the collected data, we can calculate the sample mean and standard deviation as follows,

Sample Mean:

$$
\begin{aligned}
\overline{\bar{X}} & =\frac{81.0252}{20} \\
\overline{\bar{X}} & =4.05127
\end{aligned}
$$

\section{Standard Deviation:}

We have,

$X \hat{i}=$ Observed value of sample item

$\mathrm{n}=$ Number of Observation

$\overline{\bar{X}}=$ Sample Mean

$\hat{\sigma}=$ Standard Deviation for Sample

To calculate the process standard deviation we have,

$$
\hat{\sigma}=\frac{\bar{R}}{d_{2}}
$$

Where,

$\bar{R}=$ Average of range $\quad d_{2}=2.236$ d2 from statistical control chart constant for subgroup of 5

$$
\hat{\sigma}=\frac{0.025}{2.236}=0.011
$$

Table -3 Computed Data

\begin{tabular}{|l|l|}
\hline Data & Value \\
\hline Sample Mean $(\overline{\bar{X}})$ & 4.05127 \\
\hline Standard Deviation $(\widehat{\sigma})$ & 0.011 \\
\hline Upper Specification Limit (USL) & 4.10 \\
\hline Lower Specification Limit (LSL) & 4.00 \\
\hline
\end{tabular}

\section{Estimation of Process Capability $\boldsymbol{C}_{p}$} Let,

The average of average of observed samples is $\overline{\bar{X}}$. Then, Process Capability $C_{p}$ will be,

$$
\begin{gathered}
C_{p}=\frac{(U S L-L S L)}{6 \times \widehat{\sigma}} \text { From (1) } \\
C_{p}=\frac{(4.10-4.00)}{6 \times 0.011} \\
C_{p}=1.52
\end{gathered}
$$




\section{Estimation of Capability Ratio}

The Percentage of specification width used by the manufacturing process is denoted by $C_{r}$.

(5)

$$
C_{r}=\frac{6 \times \widehat{\sigma}}{(H S L-U S L)}
$$

$$
\begin{gathered}
C_{r}=\frac{6 \times 0.011}{(4.10-4.00)} \times 100 \\
C_{r}=66 \%
\end{gathered}
$$

This means that the manufacturing process occupies $66 \%$ of specification width.

\section{Estimation of Process Capability Index $C_{p k}$}

$$
C_{p k}=\operatorname{Min}(C p u, C p l)
$$

$$
C_{p k}=\operatorname{Min}\left(\frac{(U S L-\bar{X})}{3 \sigma}, \frac{(\bar{X}-L S L)}{3 \sigma}\right)
$$

$$
C_{p k}=\operatorname{Min}\left(\frac{(4.10-4.052)}{3 \times 0.011}, \frac{(4.052-4.00)}{3 \times 0.011}\right)
$$

$$
\begin{gathered}
C_{p k}=\operatorname{Min}(1.46,1.57) \\
C_{p k}=1.46
\end{gathered}
$$

\section{Process Capability and Process Capability Index:} The recorded data of 100 samples further analyzed in MINITAB-19 statistical software. Process capability analysis in MINITAB-19 is shown in fig. 7, which provides the process capability $C_{p}$ of 1.50 and process capability index $C_{p k}$ of 1.46. The process capability analysis shows the process is in control and stable to meet the specification limits. There would be rejections of 2 adjustment screws due to falling outside the lower specification limit and 6 adjustment screws will get scrapped because the diameter is over the upper specification limit.

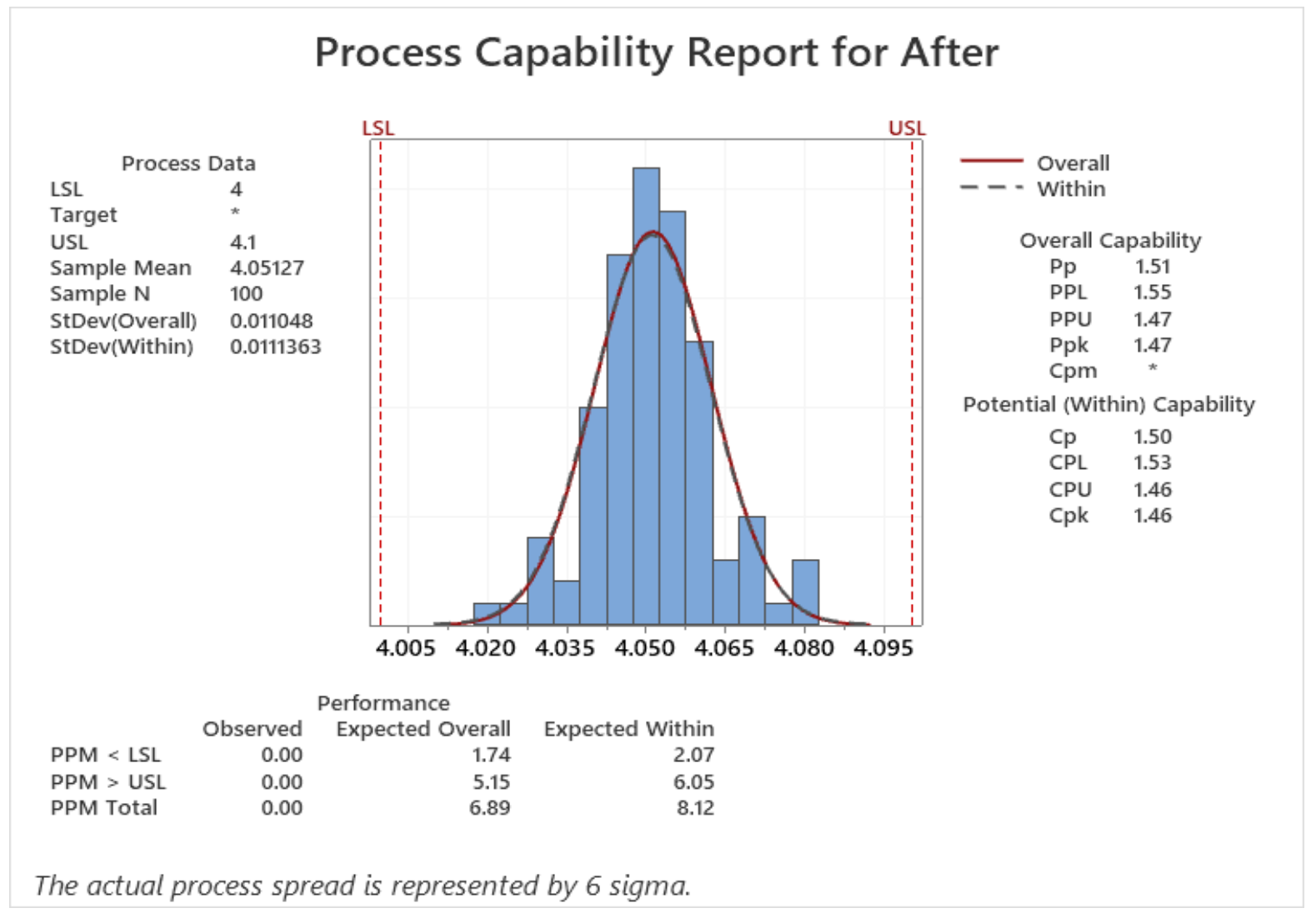

Fig.6. Process Capability Analysis Results 


\section{International Journal of Engineering Applied Sciences and Technology, 2020 \\ Vol. 5, Issue 3, ISSN No. 2455-2143, Pages 383-392 \\ Published Online July 2020 in IJEAST (http://www.ijeast.com)}

\section{B. Estimation of confidence interval of process}

The calculations of process capability and process capability index are based on a sample of 100 observations, not the whole population and hence, it leads to point estimates. As the data is normally distributed, we can calculate the confidence interval for the Process Capability Index $C_{p k}$. An approximate confidence interval of $C_{p k}$ at a $95 \%$ confidence level has been estimated under the assumption that the quality characteristic is normally distributed. Kushler and Hurley [4], Nagata Y. [5], Jose \& Jone [7] have provided a detailed treatment of the construction of approximate confidence intervals for $C_{p k}$. The following approximation as a $100(1-$ a) $\%$ confidence interval:

$$
C_{p k} \pm Z_{\frac{\alpha}{2}} \sqrt{\frac{1}{9 n}+\frac{C_{p k}^{2}}{2(n-1)}}
$$

Lower Confidence Level:

$$
C_{p k}-Z_{\frac{a}{2}} \sqrt{\frac{1}{9 n}+\frac{C_{p k}^{2}}{2(n-1)}}
$$

Higher Confidence Level:

$$
C_{p k}+Z_{\frac{\alpha}{2}} \sqrt{\frac{1}{9 n}+\frac{C_{p k}^{2}}{2(n-1)}}
$$

At $95 \%$ Confidence Level, $\propto=5 \%$

$$
\begin{gathered}
\left(1.46-Z_{\frac{0.05}{2}} \sqrt{\frac{1}{9 * 100}+\frac{1.46^{2}}{2(100-1)}}<C_{p k}<\right. \\
\left.1.46 Z_{\frac{0.05}{2}} \sqrt{\frac{1}{9 * 100}+\frac{1.46^{2}}{2(100-1)}}\right) \\
1.25<C_{p k}<1.77
\end{gathered}
$$

At $95 \%$ confidence level,

Lower Confidence Level (LCL) 1.25 is lesser than the hypothesized value of 1.33 , i.e. $1.25<1.33$ It implies that true manufacturing capability index $C_{p k}$ falls in the interval of $(1.25,1.77)$. The lower confidence level of $C_{p k}$ is below 1.33 at a $95 \%$ confidence level. Therefore, we reject the null hypothesis at a $95 \%$ confidence level and can say that even though the consecutive 5 units are in the green zone the process capability index may appear below 1.33.
C. Estimation of desired process capability and process capability index to qualify lower confidence level of $C_{p k}$ at $95 \%$ confidence level

The experiment proves we cannot say the process is in control, seeing 5 consecutive units are in the green zone. To qualify the customer's quality requirement, it is necessary to achieve the Min $\left(L C L_{c p k}\right)$ of 1.33 . Using reverse engineering approach, let Min $\left(L C L_{c p k}\right)$ is 1.33 . We can determine the target average range $\bar{R}$ and target sample mean $\overline{\bar{X}}$. Determining the approximate target average range and the sample mean will help to control the $C_{p k}$ by using control charts. From equation (8),

$$
L C L_{c p k}=C_{p k}-Z_{\frac{\alpha}{2}} \sqrt{\frac{1}{9 n}+\frac{C_{p k}^{2}}{2(n-1)}}
$$

The calculations of process capability and process capability index is based on a sample of a 100 observations.

$\therefore \mathrm{n}=100$

When $\mathrm{n}=100$ then,

$1 / 9 \mathrm{n} \approx 0$, so $1 / 9$ n is omitted from equation (8),

$$
\begin{gathered}
L C L_{c p k}=C_{p k}-Z_{\frac{\alpha}{2}} \sqrt{\frac{C_{p k}{ }^{2}}{2(n-1)}} \\
L C L_{c p k}=C_{p k}\left(1-\frac{Z_{\frac{\alpha}{2}}}{\sqrt{2(n-1)}}\right)
\end{gathered}
$$

An approximate lower confidence interval at $95 \%$ confidence level for $C_{p k}$ has $Z_{\frac{\alpha}{2}}=1.96$,

$$
\begin{gathered}
L C L_{c p k}=C_{p k}\left(1-\frac{1.96}{\sqrt{2(100-1)}}\right) \\
L C L_{c p k}=C_{p k}\left(1-\frac{1.96}{\sqrt{198}}\right) \\
L C L_{c p k}=(0.86) C_{p k}
\end{gathered}
$$

The manufacturer needs to achieve the minimum process capability index $C_{p k} 1.33$ to qualify the customer requirement. Hence,

The Lower confidence level of $C_{p k}=1.33$

$$
1.33=(0.86) C_{p k}
$$




$$
C_{p k}=\frac{1.33}{0.86}=1.55
$$

Hence, we can conclude that, in the inspection of 100 samples of a subgroup of 5 , the desired process capability index is 1.55 to achieve $\operatorname{Min}\left(L C L_{c p k}\right)$ of 1.33 .

D. A mathematical model for desired lower confidence level of process capability index $C_{p k}$

$\mathrm{N}=$ Number of Observations

$\overline{\bar{X}}=$ Sample Mean

$\hat{\sigma}=$ Standard Deviation for Sample

$S=$ Specification Width

$D=$ Design Centre

$k=$ Correction factor

Desired Lower confidence Level of $C_{p k}$,

$$
L C L_{c p k}=\frac{(0.86) \times(S-2(\bar{X}-\mu))}{S} \times \frac{S}{6 \times \hat{\sigma}}
$$

$$
L C L_{c p k}=\frac{(S-2(\overline{\bar{X}}-\mu))}{3 \times \bar{R}}
$$

1. Estimation of desired Average Range $\bar{R}$ and Sample Mean $\overline{\bar{X}}$

$$
\begin{gathered}
C_{p k}=(1-\mathrm{K}) C_{p} \\
C_{p k}=(1-\mathrm{K}) \times \frac{S}{6 \times \hat{\sigma}} \\
1.55=(1-\mathrm{K}) \times \frac{0.10}{6 \times \hat{\sigma}} \\
\hat{\sigma}=(1-\mathrm{K}) \times \frac{0.10}{6 \times 1.55}
\end{gathered}
$$

$\hat{\sigma}=(0.01) \times(1-K)$

Here, maximum standard deviation would appears when, $(1-\mathrm{K}) \approx 1$

$\therefore \quad \hat{\sigma}=0.01$

$$
\begin{gathered}
\hat{\sigma}=\frac{\bar{R}}{d_{2}} \\
\bar{R}=\hat{\sigma} \times d_{2} \\
\bar{R}=0.01 \times 2.326 \\
\bar{R}=0.023
\end{gathered}
$$

From (4)

To achieve the Min $\left(L C L_{c p k}\right)$ of 1.33 , the average range $\bar{R}$ need to maintain below $0.023 \mathrm{~mm}$ and it is necessary to maintain sample mean $\overline{\bar{X}}$ about 4.048 to 4.052 , from (12).

\section{CONCLUSION}

This case study drives a hypothesis that made think about the unwavering reliability of pre-control theory in deciding the process capability index $\left(C_{p k}\right)$. The performed case study justifies that even though the observed consecutive 5 units fell into the green zone of the pre-control chart, it isn't right to reach to the conclusion that the process capability index $C_{p k}$ of a lot will be of minimum 1.33. After testing the hypothesis based on 100 samples at a $95 \%$ confidence level, it is proved that Min $\left(L C L_{c p k}\right)$ is 1.24 , which is less than 1.33 and hence, we accepted the alternate hypothesis as even though consecutive 5 units are in green zone, process capability index $\left(C_{p k}\right)$ of the process may fall below 1.33. The width of confidence interval of $C_{p k}$ is inversely proportional to sample size $\mathrm{n}$ and hence, lowering the sample size will result into more width of confidence interval [4-5]. For the sample size of $\mathrm{n}=5$, the width of confidence interval further increases and resulted in to the confidence interval of $(0.45,2.76)$. This justifies that, increase in the sample size of sampling plan will result in to narrower width of confidence interval and more will be the accuracy to reach the true value of the process capability index $C_{p k}$. To reach the desired process capability index $C_{p k}$ of 1.33 , established a mathematical model that shapes the desired values of $\bar{R}$ and $\overline{\bar{X}}$. This $\overline{\bar{X}}$ and $\bar{R}$ can be controlled using $\bar{X}$ and $\bar{R}$ charts i.e. control charts. In the boring operation of the adjustment screw, $\bar{X}$ should be maintained in the range of 4.0489 to 4.0513 and $\bar{R}$ should be maintained below 0.023 to achieve Min $\left(L C L_{c p k}\right)$ of 1.33 , derived from equation (12). 


\section{REFERENCE}

[1] Bhote Keki R. \& Bhote Adi K. (2008), World Class Quality-Design of Experiments made Easier, More cost effective than SPC, AMA management briefing, 35-68.

[2] Nien Fan Zhang (1998), Estimating process capability indexes for auto correlated data Journal of Applied Statistics, Vol. 25, No. 4, 559-574.

[3] Bissell A. F. (1990), how reliable is your capability index? Applied Statistics, 39, 331-340.

[4] Kushler, R. H. and Hurley, P. (1992) Confidence bounds for capability indices, Journal of Quality Technology, 24, 188-195.

[5] Nagata, Y. \& Nagata H. (1991), Interval estimation for the process capability indices Journal of the Japanese Society for Quality Control, 21, 109-114.

[6] Encyclopaedia and Handbook of Process Capability Indices, A comprehensive exposition of quality control measures Vol. 12, page 50-53.

[7] Jose and Jane (2012), "Confidence Intervals for Process Capability Indices Using Bootstrap Calibration and Satterthwaite's Approximation Method Communications in Statistics-Simulation and Computation, Chapter 4, 6984.

[8] Nagata, Y. and Nagahata, H. (1992). Approximation formulas for the confidence intervals of process capability indices. Reports of Statistical Application Research, JUSE, Vol. 39, No.3, 15-29.

[9] Kurian, K.M., Mathew, T. and Sebastian, G. (2008). Generalized Confidence Intervals for Process Capability Indices in the One-Way Random Model, Metrika, 67, 8392.

[10] Bisaglia, L., Bordignon, S. and Cecchinato, N. (2010). Bootstrap Approaches for Estimation and Confidence Intervals of Long Memory Processes, Journal of Statistical Computation and Simulation, 80(9), 959-978.

[11] Chou, Y. M., Owen, D. B. and Borrego, A. S. A. (1990). Lower confidence limits on process capability indices, journal of Quality Technology, 22, 223-229.

[12] Boyles RA (1994). Process capability with symmetric tolerances, Communication Statistics Simulation Computation, 23(3), 615-643.

[13] Pearn WL, Chen KS. (1988), New generalization of the process capability index Cpk. Journal of Applied Statistics, 25 6, 801-810.

[14] Kane VE (1986), Process capability indices, Journal of Quality Technology 18, 41-52.

[15] Chan, L. K., Cheng, S. W., Spiring F. A. (1998). A new Measure of Process Capability, Journal of Quality Technology, 20, 162-175. 